\title{
Drug Combination Strategy: Pharmacokinetics and Drug-Drug Interaction Considerations in Diseased Patients
}

\author{
Nuggehally R Srinivas* \\ Zydus Research Center, Sarkhej-Bavla NH 8A, Moraiya, Ahmedabad, 382210, Gujarat, India
}

\section{Introduction}

The availability of fixed dose combinations (FDC) continues to be on the rise since they provide convenience and compliance for the disease management $[1,2]$. Given the involvement of polypharmacy in the current disease management for certain chronic ailments, the development of newer FDC combinations to benefit patients in a disease area is amply justified [3,4]. A recent publication on this important topic lays out a strategy and framework for an unequivocal and unbiased evaluation of FDC product from a pharmacokinetic perspective [5]. Some key topics of discussion in this paper includes the attributes that contribute for the dose selection of the individual FDC drug components and the key features to determine the extent (or lack) of a pharmacokinetic drug-drug interaction between the two drugs in the FDC [5]. The intent of this editorial is to provide some perspectives on the altered changes in physiology in disease patients that may likely have an influence on the pharmacokinetic disposition of drugs that are used in the combination strategy.

\section{Case Study}

The chosen disease area for this editorial was nonalcoholic steatohepatitis (NASH) since NASH continues to attract research attention given the unmet medical need. In an interesting clinical study, a triple combination therapy comprising of leucine-metforminsildenafil was used for the treatment of non-alcoholic fatty liver disease (NAFLD)/NASH [6]. The scientific rationale for this clinical investigation in NASH patients was derived from the activation of Sirt/ AMPK/NO pathway contributed in a synergistic manner by leucinemetformin-sildenafil in the combination product [6]. Although per protocol patient analysis showed high placebo response rate as compared to the two active treatment groups (low dose and high dose leucine-metformin-sildenafil combination products), a sub-group analysis of NASH patients who presented with elevated baseline ALT showed a positive read-out using PDFF (16-weeks) for the high dose leucine-metformin-sildenafil combination group vs. the placebo [6]. The authors have rationalized further investigation of the high dose product, comprising of leucine (1.1 g), metformin (500 $\mathrm{mg})$, and sildenafil (10 mg) in NASH patients [6].

\section{Perspectives}

From a clinical pharmacology consideration, it is intriguing to select individual drugs used in fixed dose therapy [5]. While molecular pathway was rationalized to be activated by the leucine-metforminsildenafil combination therapy (i.e., Sirt/AMPK/NO), there appeared to be no particular justification provided for selection of sildenafil, a well-known phosphodiesterase type 5 (PDE5) inhibitor [6]. It may be generalized that choice of PDE5 inhibitor should not have a consequence on the trial outcome; however, since the trial involves NASH patients, the pharmacokinetic disposition aspects of the PDE5 inhibitor(s) need to be considered. This is because NASH patients have been reported to exhibit impaired functioning of hepatic transporters (uptake and efflux) and cytochrome P450 enzymes (CYP); therefore, the chosen PDE5 inhibitor should not be a perpetrator to worsen the physiological roles of enzymes/transporters in NASH patients [7-9]. With respect to CYP3A4 metabolism, both sildenafil and tadalafil (another PDE5 inhibitor) being substrate drugs $[10,11]$ are expected to show differences to a similar extent in NASH patients nullifying the use of one over the other. However, based on the reported analysis with appropriate conjectures, sildenafil but not tadalafil appeared to show substrate-specific drug-drug interaction potential with bosentan, a substrate for hepatic uptake transporters $[12,13]$. It was reasoned that perhaps the inhibition of liver uptake transporters by sildenafil may have contributed for increased systemic exposure of bosentan in the clinical study [12]. Given the pathophysiology status of hepatic uptake transporters, which is typically down-regulated in NASH patients $[7,8]$, it may have been ideal to select the drug in the triple combination which may present a lower tendency for a potential drug-drug interaction. In addition, a significant advantage that tadalafil may offer over sildenafil is with respect to its long elimination half-life (sildenafil: $3.7 \mathrm{~h} v$ s. tadalafil: $17.5 \mathrm{~h}[10,11]$. Therefore, in addition to having a distinct advantage of the possibility of reduction in the daily dose of tadalafil to support the triple drug combination regimen, the use of a drug that exhibits a longer half-life may also provide an opportunity for the continuous/efficient activation of Sirt/AMPK/NO pathway.

In summary, the nuances of pharmacokinetic disposition due to altered enzymatic/transporter expression levels in disease patients need to be considered to avoid any unintended consequences of possible drug-drug interaction when newer therapeutic options including the suggested triple drug combination (i.e., leucine-metformin-sildenafil) is considered for NASH management or any disease area management.

\section{References}

1. Markham A (2018) Bictegravir: First global approval. Drugs 78: 601-606.

2. Kiang TKL (2018) Clinical pharmacokinetics and drug-drug interactions of Elbasvir/Grazoprevir. Eur J Drug Metab Pharmacokinet.

3. de Cates AN, Farr MR, Wright N, Jarvis MC, Rees K, et al. (2014) Fixed-dose combination therapy for the prevention of cardiovascular disease. Cochrane Database Syst Rev 16: CD009868.

4. Verma AA, Khuu W, Tadrous M, Gomes T, Mamdani MM (2018) Fixed-dose combination antihypertensive medications, adherence, and clinical outcomes: A population-based retrospective cohort study. PLoS Med 15: e1002584.

*Corresponding author: Nuggehally R Srinivas, PhD, FCP, Zydus Research Centre, Sarkhej-Bavla NH 8A, Moraiya, Ahmedabad 382210, Gujarat, India, Tel: 918066628801; E-mail: nuggehally.srinivas@zyduscadila.com

Received July 17, 2018; Accepted July 19, 2018; Published July 27, 2018

Citation: Srinivas NR (2018) Drug Combination Strategy: Pharmacokinetics and Drug-Drug Interaction Considerations in Diseased Patients. J Bioequiv Availab 10: e87. doi: 10.4172/0975-0851.1000e87

Copyright: (c) 2018 Srinivas NR. This is an open-access article distributed under the terms of the Creative Commons Attribution License, which permits unrestricted use, distribution, and reproduction in any medium, provided the original author and source are credited. 
Citation: Srinivas NR (2018) Drug Combination Strategy: Pharmacokinetics and Drug-Drug Interaction Considerations in Diseased Patients. J Bioequiv Availab 10: e87. doi: 10.4172/0975-0851.1000e87

5. Dash RP, Rais R, Srinivas NR (2018) Key pharmacokinetic essentials of fixed-dosed combination products: Case studies and perspectives. Clin Pharmacokinet 57: 419-426.

6. Chalasani N, Vuppalanchi R, Rinella M, Middleton MS, Siddiqui MS, et al. (2018) Randomised clinical trial: a leucine-metformin-sildenafil combination (NS-0200) vs placebo in patients with non-alcoholic fatty liver disease. Aliment Pharmacol Ther.

7. Clarke JD, Hardwick RN, Lake AD, Canet MJ, Cherrington NJ (2014) Experimental nonalcoholic steatohepatitis increases exposure to simvastatin hydroxy acid by decreasing hepatic organic anion transporting polypeptide expression. J Pharmacol Exp Ther 348: 452-458.

8. Canet MJ, Merrell MD, Hardwick RN, Bataille AM, Campion SN, et al. (2015) Altered regulation of hepatic efflux transporters disrupts acetaminophen disposition in pediatric nonalcoholic steatohepatitis. Drug Metab Dispos 43 829-835.
9. Fisher CD, Lickteig AJ, Augustine LM, Ranger-Moore J, Jackson JP, et al. (2009) Hepatic cytochrome P450 enzyme alterations in humans with progressive stages of nonalcoholic fatty liver disease. Drug Metab Dispos 37 2087-2094.

10. Walker DK, Ackland MJ, James GC, Muirhead GJ, Rance DJ, et al. (1999) Pharmacokinetics and metabolism of sildenafil in mouse, rat, rabbit, dog and man. Xenobiotica 29: 297-310.

11. Forgue ST, Patterson BE, Bedding AW, Payne CD, Phillips DL, et al. (2006) Tadalafil pharmacokinetics in healthy subjects. Br J Clin Pharmacol 61: 280-288.

12. Srinivas NR (2009) Substrate-specific pharmacokinetic interaction between endothelin receptor antagonists and phosphodiesterase-5 inhibitorsassembling the clues. Br J Clin Pharmacol 67: 475-477.

13. Srinivas NR (2016) Clinical drug-drug interactions of bosentan, a potent endothelial receptor antagonist, with various drugs: Physiological role of enzymes and transporters. Gen Physiol Biophys 35: 243-258. 